\title{
IDENTIDADES CONSTRUÍDAS E RECONSTRUÍDAS: A PERSPECTIVA DO OUTROE A IMPOSIÇÃO DE VALORES À CULTURA INDÍGENA
}

\author{
João Luis Pereira Ourique ${ }^{1}$
}

Resumo: Este trabalho parte do entendimento de que a questão da identidade é vista não como conceito unificador, mas como problematização do que se entende como formação cultural. Essa discussão se traduz, assim, como o principal elemento que sustenta um processo de cunho hermenêutico, refletindo as diversas interpretações acerca da construção do eu e do Outro. $O$ entrecruzamento de olhares a partir de culturas distintas - entre o indígena e o branco colonizador - evidencia o descompasso e as contradições decorrentes desse processo de inculcação de valores e da tentativa de apagamento de uma forma de pensar a si mesmo.

Palavras-chaves: cultura - identidade - valores - imposição.

Abstract: This work starts from the understanding that the question of identity is seen not as a unifying concept, but as questioning of what is understood as cultural formation. This discussion is translated as well, as the main element that sustains a process of hermeneutic nature, reflecting the various interpretations of the construction of the self and the Other. The interchange of looks from different cultures - between indigenous and white settler - highlights the mismatch and contradictions arising from this process of inculcation of values and the attempted erasure of a way of thinking about yourself.

Keywords: culture - identity - values - imposition.

Partimos do entendimento de que identidade é um conceito que apresenta várias perspectivas e possibilidades, dependendo, inclusive, do ponto de vista acerca de considerações em comum. Assim, a dimensão sob a qual abordaremos esse tema se pautará na sua problematização e não na(s) sua(s) definição(ões). Naturalizamos os conceitos e nos acostumamos com os mesmos de tal forma que se tornam tão comuns a ponto de serem vistos como entidades sempre presentes e inquestionáveis. Questionamos os nossos conceitos, alguém pode afirmar - e, é óbvio, corretamente -, mas dificilmente conseguimos estabelecer parâmetros fora dos paradigmas já instaurados a priori. Questionamos a partir de um lugar comum, que inclui todo um processo formativo, toda uma carga cultural que nos atravessa e que nos completa ${ }^{2}$. A mesma

\footnotetext{
${ }_{1}^{1}$ Professor Adjunto do Centro de Letras e Comunicação da Universidade Federal de Pelotas (UFPEL).

${ }^{2}$ Essa reflexão se ampara nas palavras de Walter Benjamin na tese 1 do ensaio Sobre o conceito da história: "Conhecemos a história de um autômato construído de tal modo que podia responder a cada lance de um jogador de xadrez com um contralance, que lhe assegurava a vitória. um fantoche vestido à turca,
} 
carga que é capaz de instigar a reflexão sobre esses paradigmas é também a que nos vincula de forma quase indissolúvel a esses modelos de pensamento. "Quase" é a palavra certa, pois sempre há possibilidades de um pensar para além e fora desses aprisionamentos. O paradoxo que ocorre é que ao tentarmos nos afastar do que nos forma para discutirmos a identidade, acabamos por definir a partir de visões generalistas das nossas próprias visões deformadas, assim como quando sucumbimos a um único quadro de referência para tratar de algo muito próximo e que não conseguimos nos afastar minimamente. Esse aspecto traiçoeiro do conceito, conforme Zilá Bernd (1992) apresenta - e que aqui nos propomos à ampliação dessa abordagem, reconhecendo que a pluralidade desta inserção pode, muito comumente, também ser barrada pelos limitadores interpretativos da razão instrumentalizada -, é o elemento em que procuraremos apresentar para introduzir a discussão e não para resolvê-la.

A entrevista dada pelo sociólogo polonês Zygmunt Bauman a Benedetto Vecchi apresenta exatamente esse aspecto contraditório acerca do tema da identidade. Antes de ser formulada a primeira questão, Bauman comenta sobre o título de doutor honoris causa que recebeu:

Segundo o antigo costume da Universidade Charles, de Praga, o hino nacional do país da pessoa que está recebendo o título de doutor honoris causa é tocado durante a cerimônia de outorga. Quando chegou a minha vez de receber essa honraria, pediram-me que escolhesse entre os hinos da Grã-Bretanha e da Polônia... Bem, não me foi fácil encontrar a resposta. A Grã-Bretanha foi o país que escolhi e pelo qual fui escolhido por meio de uma oferta para lecionar, já que eu não poderia permanecer na Polônia, país em que nasci, pois tinham me tirado o direito de ensinar. Mas lá, na Grã-Bretanha, eu era um estrangeiro, um recém-chegado - não fazia muito tempo, um refugiado de outro país, um estranho. Depois disso naturalizeime britânico, mas, uma vez recém-chegado, será possível abandonar essa condição algum dia? (...) Então, talvez devessem tocar o hino polonês? Mas isso também significaria um ato de fingimento: trinta anos antes da cerimônia de Praga eu tinha sido privado de minha cidadania polonesa. Minha exclusão foi oficial, promovida e confirmada pelo poder habilitado a separar quem está "dentro" de quem está "fora", quem faz parte de quem não faz - e assim eu não tinha mais o direito ao hino nacional polonês... Janina, minha companheira por toda a vida e pessoa que já refletiu muito sobre as armadilhas e privações da autodefinição (...), encontrou a

com um narguilé na boca, sentava-se diante do tabuleiro, colocado numa grande mesa. Um sistema de espelhos criava a ilusão de que a mesa era totalmente visível, em todos os seus pormenores. Na realidade, um anão corcunda se escondia nela, um mestre no xadrez, que dirigia com cordéis a mão do fantoche. Podemos imaginar uma contrapartida filosófica desse mecanismo. O fantoche chamado 'materialismo histórico' ganhará sempre. Ele pode enfrentar qualquer desafio, desde que tome a seu serviço a teologia. Hoje, ela é pequena e feia e não ousa mostrar-se." (1986, p. 222).

Revista Eletrônica Literatura e Autoritarismo, no 21- Janeiro-Junho de 2013 - ISSN 1679-849X |76 http://cascavel.ufsm.br/revistas/ojs-2.2.2/index.php/LA/about/index 
solução: por que não o hino da Europa? (...) Europeu, sem dúvida, eu era, nunca tinha deixado de ser (...) Nossa decisão de pedir que tocassem o hino europeu foi simultaneamente "includente" e "excludente". (...) Tirava da pauta uma identidade definida em termos de nacionalidade - o tipo de identidade que me foi negado e tornado inacessível. (2005, p. 15-16)

No entanto, essa justificativa de Bauman confronta o que ele mesmo define, ou seja, o sociólogo (polonês?) afirma que a "idéia de identidade nasceu da crise do pertencimento e do esforço que esta desencadeou no sentido de transpor a brecha entre o 'deve' e o 'é' e erguer a realidade ao nível dos padrões estabelecidos pela idéia - recriar a realidade à semelhança da idéia" (2005, p. 26). Com isso, surge o paradoxo indissolúvel da própria condição humana. O pensador voltado para a discussão da identidade e de toda a carga conceitual e impositiva de condutas e valores acaba por sucumbir a esse sentimento de pertença, ainda que procurando uma espécie de consenso e de legitimação de suas escolhas. Seria mais natural ignorar os hinos nacionais - por ser um "estranho" ou uma espécie de pária pelo poder oficial de seu país natal - do que optar por uma terceira opção. É absurdo ter que escolher, ter que definir a identidade própria a partir de configurações outras que não o próprio pensar? Parece-nos que se não é impossível, é, no mínimo, extremamente difícil.

Nessa linha de raciocínio, Hugo Achugar discute alguns problemas do pensamento crítico literário latino-americano ao relacionar a questão das "histórias locais".

A "história local" de um sujeito social não e a mesma "história local" de outro, mesmo que ambos pertençam à mesma comunidade; ou, dito de outra forma, não somente se produz em função de uma "história local", como também em função do "posicionamento" - os "interesses locais e concretos" - dentro das ditas histórias locais. (...) O sujeito social pensa, ou produz conhecimento, a partir de sua "história local", ou seja, a partir do modo que "lê" ou "vive" a "história local", em virtude das suas obsessões e do horizonte ideológico em que está situado. (2006, p. 28-29).

E se as histórias locais estão marcadas por uma visão comum de julgamento, de um sentido amplo de submissão a um valor cultural específico e que não evidencia a particularidade de uma cultura? O elemento literário - entendido como o contar essas histórias próprias de uma comunidade ou de um determinado grupo social que partilhou experiências singulares dentro de uma comunidade - se encontra presente: tanto como fenômeno artístico quanto testemunho da cultura. Cabe aqui, portanto, definirmos com clareza a nossa percepção e inserção no tema a ser discutido: imposição de valores à 
cultura indígena. $\mathrm{O}$ argumento de que os povos indígenas também possuem literatura, além de ser válido e necessário, necessita ser esclarecido para que, em nome de uma suposta valorização, não se incorra em uma tentativa de apagamento cultural. A pergunta feita por Walter Ong - Você disse "literatura oral"?, somente dá um maior dinamismo à questão em si, ou seja, não simplifica o problema, mas o confronta:

A concentração do saber em textos teve conseqüências ideológicas. Em
virtude de sua atenção dirigida aos textos, os estudiosos muitas vezes
passaram a presumir, com freqüência irrefletidamente, que a verbalização
oral era essencialmente idêntica à escrita com a qual normalmente
lidavam, e que as formas artísticas orais eram, para todos os efeitos,
simplesmente textos, salvo o fato de não terem sido registradas por
escrito. Criou-se a impressão de que, distintas do discurso (governado por
regras teóricas e escritas), as formas artísticas orais eram
fundamentalmente desajeitadas e indignas de estudo sério.(...) Não é fácil
imaginar a tradição puramente oral ou a oralidade primária de forma exata
e significativa. A escrita faz com que as "palavras" pareçam semelhantes
às coisas porque pensamos nas palavras como as marcas visíveis que
comunicam as palavras aos decodificadores: podemos ver e tocar tais
"palavras" inscritas em textos e livros. As palavras escritas são resíduos. A
tradição oral não tem tais resíduos ou depósitos. Quando uma história oral
contada e recontada não está sendo narrada, tudo que dela subsiste é seu
potencial de ser narrada por certos seres humanos. Estamos, quase todos
nós (aqueles que lêem textos como este), tão impregnados da cultura
escrita que raramente nos sentimos à vontade numa situação em que a
verbalização é tão pouco semelhante a alguma coisa, como ocorre na
tradição oral. (1998, p. 18-20).

A ampliação do conceito de literatura com o objetivo de abranger os fenômenos culturais que não eram percebidos como tal tem uma intenção positiva, no entanto, uma questão conceitual tão complexa não pode ser entendida de forma resumida. Ampliar o paradigma para abranger e valorizar outros aspectos da cultura é relevante, o que não pode ocorrer é a simplificação de suas variantes que o conceito tenta subordinar em suas fronteiras - que, na maioria das vezes, são menos elásticas do que deveriam. "Literatura oral" é um conceito problemático quando atenua as variantes dessa oralidade. Não temos pretensão de elaborar um conceito novo, mas apenas de discutir a indefinição do mesmo, de transitar nesse espaço, de dialogar com as culturas e de refletir, a partir do ponto de vista normativo e dominante, algumas situações peculiares.

Essa busca por uma narrativa de cunho autointerpretativo se insere no que Antonio Cornejo Polar mostrou como uma das possibilidades de realização de uma crítica latinoamericana: "a que se relaciona com o tratamento crítico das literaturas sujeitas a um 
duplo estatuto sociocultural" (p. 157). Discutindo a noção de que a "literatura nacional seria um espaço criticamente inteligível" (p. 158), podemos afirmar também que o conceito de literatura nacional se apresenta de forma contraditória, pois traz consigo variantes e conceitos que vão do particular ao universal, trazendo definições que consolidam visões de sujeitos antes mesmo de narrá-las. Partindo de uma citação de José Carlos Mariátegui ${ }^{3}$, Cornejo Polar destaca a separação entre o universo indigenista e o indígena e insere a leitura sociológica proposta por Ángel Rama que se propôs a entender o indigenismo "como resultado da ascensão de grupos minoritários da classe média baixa, que usam as reivindicações indígenas como reforço e legitimação de suas próprias demandas contra o sistema social imposto de cima pela classe exploradora" (2000, p. 172). No entanto, apesar de concordar com a premissa básica de Rama, Cornejo Polar acrescenta que:

o melhor indigenismo, não apenas assume os interesses do campesinato indígena: assimila também, em grau diverso, tímida ou audazmente, certas formas literárias que pertencem organicamente ao referente. Compreendese que esta dupla assimilação, de interesses sociais e de formas estéticas, constitui o correlato dialético da imposição que sofre o universo indígena por parte do sistema produtor do indigenismo: é, por assim dizer, sua resposta. Daí se desprende que o trabalho crítico sobre o indigenismo não pode continuar realizando-se em função exclusiva do critério de "interioridade". É habitual, de fato, que a crítica examine os textos indigenistas em termos de uma relação mimética entre representação literária e referente, pressupondo que esta relação será tanto mais valiosa e esclarecedora quanto mais interior ("de dentro") seja a perspectiva do autor. Embora o indigenismo tenha uma inequívoca vocação realista, e embora suas obras pretendam efetivamente plasmar representações fidedignas do mundo indígena, o certo é que - ao lado desta capacidade mimética - o indigenismo ensaia outra forma de autenticidade, mais complexa, que deriva da mencionada assimilação de certas formas próprias do referente, assimilação que implica um sutil processo artístico, obviamente tão importante - ou mais - quanto o cumprimento da decisão realista. (2000, p. 174).

\footnotetext{
${ }^{3}$ A citação de Mariátegui é: "e a maior injustiça em que poderia incorrer um crítico seria qualquer apressada condenação da literatura indigenista, por sua falta de autoctonomismo integral ou a presença, mais ou menos acusada em suas obras, de elementos de artifício na interpretação e na expressão. A literatura indigenista não pode dar-nos uma versão rigorosamente verista do índio. Tem de idealizá-lo e estilizá-lo. Tampouco pode dar-nos sua própria 'ânima'. É ainda uma literatura de mestiços. Por isso chama-se indigenista e não indígena. Uma literatura indígena, se deve vir, virá em seu tempo. quando os próprios índios estiverem em condição de produzí-la" (Apud. CORNEJO POLAR, 2000, p. 168). Cornejo Polar chama a atenção para o aspecto discutível das duas últimas frases da citação, mas a questão da escrita indígena é que está em jogo ao lado da sua representação. No entanto, a valorização de uma literatura indigenista deve ser feita por ela mesma e não por uma suposta evolução da "literatura oral" indígena.
} 
Essa discussão se volta para um cenário no qual existe uma aproximação sociológica e uma tentativa de identificação com a realidade do referente indígena. Os dois exemplos que trataremos a seguir se pautam em uma perspectiva cultural e não propriamente literária - seja indigenista ou indígena -, mas parte das configurações problemáticas e dos desdobramentos dos mesmos na interpretação e nas definições de identidades.

O primeiro exemplo vem do período das Missões Jesuíticas no Rio Grande do Sul e da inserção cristã no pensamento indígena. A religiosidade católica, advinda do trabalho missionário dos jesuítas se incorporou de tal forma ao imaginário da região que limitou em muitos casos o aspecto opressor dessa historicidade. A lenda de Tupan-Cy-Retan ${ }^{4}-$ que dá nome ao município de Tupanciretã, localizado na região central do estado do Rio Grande do Sul - aponta essa tentativa de apagamento cultural. Ainda que percebamos o caráter belo e singular atribuído à lenda, todo o cenário que a cerca apenas legitima 0 aspecto de superioridade do branco em relação ao bárbaro, conforme a citação acerca da apropriação e adaptação da língua indígena aos ritos e religiosidade cristãos:

D. Pedro II, certa vez, em Roma, conseguiu uma cópia manuscrita de diversas estrofes de Anchieta. Entre essas quadras, encontra-se esta:

O' Virgem Maria

Tupan-ci-etê

Aba pe ara pora

Oicó endê iabê

que, traduzida, quer dizer: "O' Virgem Maria, Mãe de Deus verdadeira, os homens deste mundo estão muito bem convosco". (ORNELLAS, 1934, p. 73).

Essa visão está legitimada no imaginário coletivo, sendo aceito sem maiores ressalvas. E essa legitimação naturaliza as imagens decorrentes desse processo, ou seja,

\footnotetext{
4 "A fazenda jesuítica, apenas assinalada pela capelinha tôsca, já existia no alto de um coxilhão deserto. E as árvores do mato crioulo, á tarde, projetavam-lhe a sombra larga de suas ramarias. Ao lado, sob o amparo de uma cruz modesta, mal resistia á fúria das tempestades, um rancho pobre, coberto de palha, que tinha a finalidade amiga de acolher os poucos viandantes que por alí passavam. o local nada mais era do que um pôsto de São João. Dentro da capelinha, tão pobre como esquecida, apenas uma imagem também tôsca, enfeitava a tábua erguida como altar. Era uma imagem da Madona dos Céus, da Senhora dos crentes. Um dia, em que pelos caminhos mal delineados da serra, passavam um Missionário e alguns índios, uma tempestade os colheu nas proximidades do planalto da Coxilha Grande. A noite chegava e, com ela, o pânico e o terror. Quando a desorientação desesperava o padre e os poucos índios companheiros, um relâmpago lhes mostrou, na fímbria do horizonte, em plena, noite, um vulto próximo, mal definido. A silhueta que os relâmpagos mostravam, perto, era da imagem da Madona, exposta ao furor da tempestade, que arrebatára da capela pequenina a cobertura frágil. O sacerdote, cheio de alegria cristã, exclamou: "TupanCi!" E os índios, aterrados, repetiram: "Tupan-ci-retan!". Nenhum batismo mais original do que êste." (ORNELLAS, 1934, p. 75-76)
} 


\section{Literatura e Autoritarismo}

que houve uma evolução da religiosidade indígena ao incorporar o seu opressor - em uma espécie de sincretismo que ignora a outra religiosidade, se atendo apenas a uma maneira peculiar de utilizar a língua do selvagem. A escultura presente em uma das principais vias de acesso ao município representa, para um olhar mais crítico, o simbolismo dessa opressão - a figura de dois índios carregando a Cruz de Lorena, símbolo das Missões Jesuíticas:

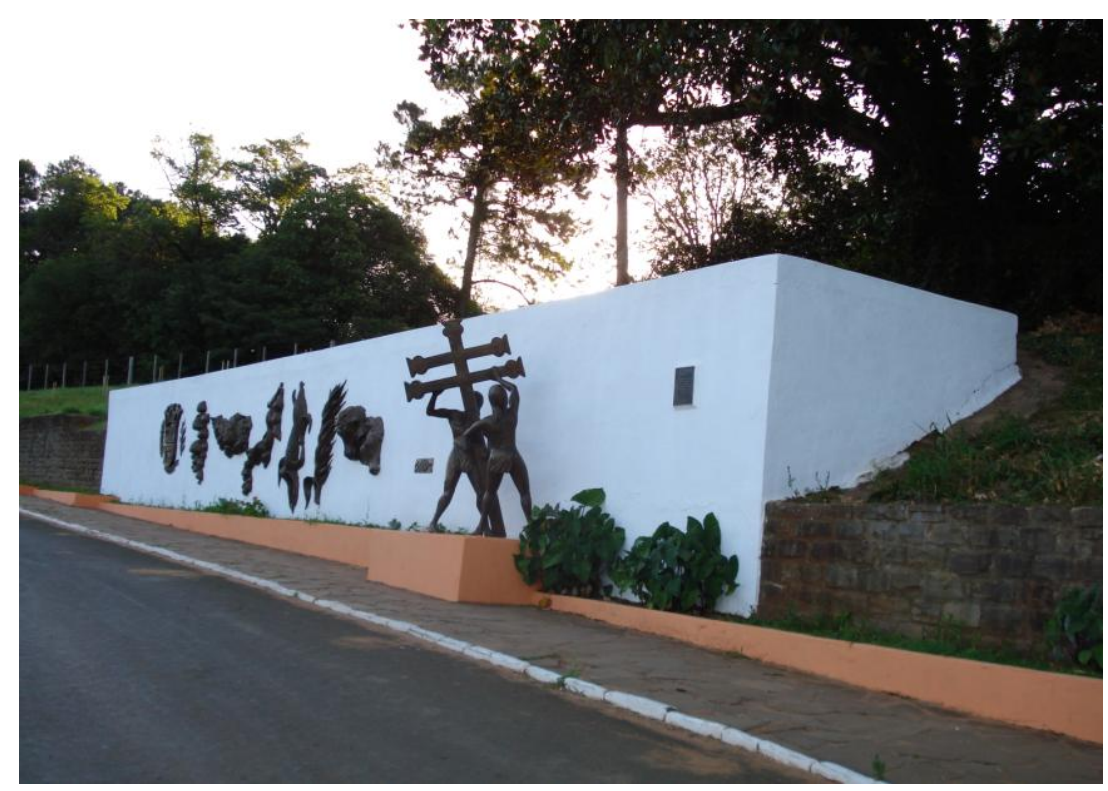

O outro exemplo vem do estado de Mato Grosso do Sul, região que concentra 73.295 índios, segunda maior população indígena do Brasil, ficando apenas atrás do estado do Amazonas, com uma população de 168.680, segundo dados do último senso do IBGE. Em virtude da presença indígena em várias instâncias sociais - incluindo a administrativa e econômica para além dos espaços de reserva - percebemos uma preocupação com a desigualdade em que os mesmos vivem. No entanto, devemos sempre perceber que qualquer conceito implica uma carga problemática quando não bem administrado ou quando tende a resolver um determinado conflito ideológico ou cultural. Em nome de uma valorização dessas comunidades e da preservação da identidade indígena, o pensamento indigenista (de fora para dentro) cunhou o termo não índio em substituição ao branco.

O intuito dessa nova denominação era quebrar com a hierarquia dominante ao utilizar os termos branco e índio, situação em que o índio sempre se apresentava em inferioridade pela questão histórica. Ao se referir aos diferentes grupos étnico-culturais, os 
termos não índio e índio apresentavam-se horizontalmente e não mais verticalmente, criando, segundo a perspectiva positiva dessa inserção, uma igualdade ao dirimir o preconceito instaurado nas denominações anteriores.

Devemos salientar que a crítica a essa perspectiva não é o fato da mesma buscar dirimir esses preconceitos, mas da forma como foi construída. Ocorre, em nome de valorizar uma identidade, uma espécie de apagamento de sua filosofia cultural, ou seja, o reconhecimento de si a partir da negação do Outro (o Outro visto como um não eu) é base do pensamento do branco, do ocidental e não uma regra geral dos processos de construção identitárias. Ainda que haja essa percepção em várias das culturas que compõem esse cenário maior, a sua generalização acaba por impor uma visão específica de entender a realidade a partir de outras instâncias e não de sua própria relação com a cultura familiar e o estranho e diferente a ela.

Essa relação entre a identidade e a diferença deve ser problematizada continuamente. Pensar a identidade apenas em oposição ao não ser implica em uma visão limitada do que seja a relação entre cultura e significado. Kathryn Woodward afirma que só "podemos compreender os significados envolvidos nesses sistemas se tivermos alguma ideia sobre quais posições-de-sujeito eles produzem e como nós, como sujeitos, podemos ser posicionados em seu interior" (In: SILVA, 2000, p. 17). Essa busca pela compreensão de como os significados decorrentes das práticas de significação dão sentido à identidade individual e coletiva não deve se constituir em um distanciamento de uma necessária visão crítica. Woodward afirma que as identidades são construídas em oposição ao "forasteiro", destacando, nessa linha de fundamentação que a produção da diferença ocorre por meio de posições binárias, sendo essa concepção fundamental para que se possa compreender o processo de construção cultural das identidades. Apresenta, no entanto, um importante alerta para que essa reflexão não sucumba ao viés simplista das conclusões excludentes:

Os sistemas sociais e simbólicos produzem as estruturas classificatórias que dão um certo sentido e uma certa ordem à vida social e as distinções fundamentais - entre nós e entre eles, entre o fora e o dentro, entre o sagrado e o profano, entre o masculino e o feminino - que estão no centro dos sistemas de significação da cultura. Entretanto, esses sistemas classificatórios não podem explicar, sozinhos, o grau de investimento pessoal que os indivíduos têm nas identidades que assumem. A discussão das teorias psicanalíticas sugeriu que, embora as dimensões sociais e 
simbólicas da identidade sejam importantes para compreender como as posições de identidade são produzidas, é necessário estender essa análise, buscando compreender aqueles processos que asseguram 0 investimento do sujeito em uma identidade. (WOODWARD, In: SILVA, 2000, p. 68).

Dando continuidade a essa discussão, Tomaz Tadeu da Silva problematiza a questão da identidade ser pensada sob o viés da exclusão e da oposição entre o que é e aquilo que não é, enfatizando que essa suposta facilidade decorre de uma primeira aproximação, cuja limitação acaba nivelando a percepção da diferença ao mesmo procedimento, influenciando e definindo a ideia de exclusão como intrínsecas a esses conceitos.

Já sabemos que a identidade e a diferença são o resultado de um processo de produção simbólica e discursiva. O processo de adiamento e diferenciação linguísticos por meio do qual elas são produzidas está longe, entretanto, de ser simétrico. A identidade, tal como a diferença, é uma relação social. Isso significa que sua definição - discursiva e linguística está sujeita a vetores de força, a relações de poder. Elas não são simplesmente definidas; elas são impostas. Elas não convivem harmoniosamente, lado a lado, em um campo sem hierarquias; elas são disputadas. (SILVA, 2000, p. 81).

Ao concordarmos que a identidade e a diferença estão estreitamente associadas a sistemas de representação, retomamos aqui o propósito deste ensaio que é o de problematizar o próprio sistema de representação. A ideia de exclusão (de ver o Outro como um não eu) passa por inúmeras variantes, desde a da aceitação/negação individual até as relações de poder atuando em prol das estruturas de dominação a serviço de elites econômicas, políticas, religiosas, culturais, etc. O problema maior - ao analisarmos e confrontarmos o problema da identidade com os paradigmas conceituais disponíveis e legitimados - é verificarmos suas incongruências e a constante necessidade construirmos a identidade antes de compreendê-la.

Essa reflexão que apresentamos evidencia o quanto ainda estamos engatinhando na compreensão do fenômeno identitário acerca da cultura indígena. Tanto a leitura crítica da história quanto o olhar atento para o momento presente são necessários para o entendimento de, ao menos, algumas dimensões desse grande debate. $\mathrm{O}$ que podemos afirmar é que não é possível subtrair aspectos pontuais e generalizá-los - mesmo em 
nome de uma igualdade e valorização - sem deixarmos rastros capazes de serem seguidos com outros fins.

\section{Referências:}

ACHUGAR, Hugo. Sobre o balbucio teórico latino-americano. In: Planetas sem boca. Tradução Lyslei Nascimento. Belo Horizonte: Ed. UFMG, 2006.

BAUMAN, Zygmunt. Identidade. Tradução Carlos Alberto Medeiros. Rio de Janeiro: Jorge Zahar Editor, 2005.

BENJAMIN, Walter. Sobre o conceito da história. In: . Magia e técnica, arte e política. 2. ed. Tradução Paulo Sérgio Rouanet. São Paulo: Brasiliense, 1986.

BERND, Zilá. Identidade. In: . Literatura e identidade nacional. Porto Alegre: Ed. UFRGS, 1992.

CORNEJO POLAR, Antonio. O indigenismo e as literaturas heterogêneas: seu duplo estatuto social. In: O condor voa: literatura e cultura latino-americanas. Organização: Mario Valdés. Tradução: Ilka Valle de Carvalho. Belo Horizonte: Ed. UFMG, 2000.

ONG, Walter. Oralidade e cultura escrita: a tecnologização da palavra. Tradução Enid Abreu Dobránszky. Campinas: Papirus, 1998.

ORNELLAS, Manoelito de. Tupan-Cy-Retan. São Paulo: São Paulo Editora Ltda., 1934.

SILVA, Tomaz Tadeu da (Org.). Identidade e diferença. A perspectiva dos estudos culturais. 5. ed. Petrópolis: Vozes, 2000. 